\title{
Letter \\ Stroke volume and passive leg raising predict volume responsiveness in ICU patients: who is actually responsive? Jasper van Bommel and Eva Klijn
}

Department of Intensive Care, Erasmus Medical Center, 's Gravendijkwal 230 PO Box 3000 CA Rotterdam the Netherlands

Corresponding author: Jasper van Bommel, j.vanbommel@erasmusmc.nl

Published: 30 October 2009

This article is online at http://ccforum.com/content/13/5/423

(c) 2009 BioMed Central Ltd

See related research by Thiel et al., http://ccforum.com/content/13/4/R111
Critical Care 2009, 13:423 (doi:10.1186/cc8139)

\section{References}

1. Thiel SW, Kollef MH, Isakow W: Non-invasive stroke volume measurement and passive leg raising predict volume responsiveness in medical ICU patients: an observational cohort study. Crit Care 2009, 13:R111.

coworkers [1], who clearly demonstrate how a completely non-invasive technique can be used to determine changes in cardiac stroke volume in response to a passive leg raise maneuver (PLR) and actual fluid administration. Still, I have some questions.

First, we wonder why the authors chose to enroll only the patients who were a priori considered to require volume expansion. Especially with the use of a non-invasive technique and the PLR being part of routine practice, it would be very instructive to know which and how many patients from the general ICU population are actually fluid responsive or likely to be exposed to excess fluid administration.

Second, why did the authors perform the volume expansion after the PLR with the patients again in the semi-recumbent position? Patients are put in this position to mobilize more volume for the actual PLR [2], but the stroke volume response is studied in the supine position (which is also the normal position for most ICU patients). Because of a decreased preload it is very likely that more fluid has to be administered to these patients to evoke a similar response in stroke volume

Finally, did the authors anticipate this increased fluid requirement when they administered a rather large volume expansion ( $\geq 500 \mathrm{ml}$ ) in relation to the volume they estimated to be mobilized with the PLR (150 to $200 \mathrm{ml}$ )? Could it be possible that these differences have influenced the sensitivity and specificity of calculations?

\section{Competing interests}

The authors declare that they have no competing interests.
2. Monnet X, Teboul J: Passive leg raising. Int Care Med 2008, 34:659-663. 